\title{
KOMPARASI SIMULASI KONTROL SUHU DAN LEVEL AIR PADA TANAMAN HIDROPONIK MENGGUNAKAN SISTEM FUZZY MAMDANI DAN ADAPTIVE NEURO FUZZY INFERENCE SYSTEM (ANFIS)
}

\author{
Endah Fitriani ${ }^{1}$ Normaliaty $^{\text {Fithri }}{ }^{2}$ \\ ${ }^{1,2}$ Jurusan Teknik Elektro, Fakultas Teknik, Universitas Bina Darma, Palembang, Indonesia \\ Email: ${ }^{1}$ endahfitriani@ binadarma.ac.id , ${ }^{2}$ normaliaty@binadarma.ac.id
}

\begin{abstract}
ABSTRAK
Dalam menanam hidroponik ada beberapa hal yang harus diperhatikan agar pertumbuhan tanaman tidak terganggu, antara lain adalah pengontrolan suhu dan level air. Dengan menggunakan simulasi sistem kontrol fuzzy kita dapat mengatur kerja atap dan pompa air agar sesuai dengan perubahan suhu dan level air. Selain dengan menggunakan sistem kontrol fuzzy kita juga dapat menggunakan ANFIS dalam memprediksi kontrol atap dan pompa air. Dari hasil simulasi diperoleh terdapat selisih untuk atap antara 0.001 sampai 0.02 , sedangkan untuk pompa air terdapat selisih antara 0.006 sampai dengan 0.01. Dengan rata-rata error yang diperoleh pada saat menggunakan ANFIS adalah 0,0079496 untuk kontrol atap dan 0,01296 untuk kontrol pompa air.
\end{abstract}

Kata kunci: Suhu, Level Air, Mamdani, dan ANFIS

\begin{abstract}
ABSTRACK
In hydroponic planting, there are several things that must be considered so that plant growth is not disturbed, including controlling the temperature and water level. By using a fuzzy control system simulation we can adjust the work of the roof and the water pump to suit changes in temperature and water level. Apart from using the fuzzy control system, we can also use ANFIS in predicting roof control and water pumps. From the simulation results, it is found that there is a difference for the roof between 0.001 to 0.02 , while for the water pump there is a difference between 0.006 to 0.01 . With the average error obtained when using ANFIS is 0.0079496 for roof control and 0.01296 for water pump control.
\end{abstract}

Keywords: Temperature, WaterLevel, Mamdani and ANFIS

\section{PENDAHULUAN}

Hidroponik merupakan budidaya tanaman yang memanfaatkan air untuk memenuhi kebutuhan nutrisi bagi tanaman tanpa menggunakan tanah. Sistem hidronik dsangat cocok diterapkan pada daerah yang memiliki pasokan air dan lahan yang terbatas, contohnya adalah perkotaan. Pada sistem hidroponik, ada beberapa hal perlu diperhatikan antara lain adalah suhu dan level air. Hal ini diperlukan agar proses pertumbuhan tanaman hidroponik tidak terganggu karena kurangnya volume air atau intensitas cahaya matahari yang terlalu tinggi . Teknik kendali fuzzy telah banyak digunakan diberbagai aplikasi mulai dari industri, elektonika rumah tangga, robot dan lain-lain. Logika fuzzy merupakan pengembangan dari logika primitif yang hanyan mengenal dua keadaan, yaitu "ya" atau "tidak". Dengan adanya logika fuzzy, dapat mengenal peubah-peubah linguistik seperti agak dingin, dingin, sangat dingin dan sabagainya, sehingga aplikasi logika fuzzy akan menyebabkan sistem lebih adaptif [1]. Metode neuro-fuzzy dalam bidang pengendalian telah banyak digunakan [2]. Metode pengendalian dengan menerapkan prinsip logika fuzzy disebut FLC (fuzzy logic controller). Cara kerja pengendali ini mirip dengan seorang operator kendali, tidak memperhatikan struktur internal plant, hanya mengamati error sebagai selisih antara setpoint dengan keluaran sistem dan mengubah setting panel kendali untuk meminimalkan error tersebut. Sebuah FLC terdiri atas unit fuzifikasi, basis pengetahuan fuzzy, mesin keputusan fuzzy dan unit defuzifikasi. ANFIS adalah penggabungan dari mekanisme Fuzzy Inference System (FIS) yang dijelaskan dalam arsitektur jaringan saraf. Arsitektur dan 
prosedur pembelajaran yang mendasari ANFIS disajikan, yaitu sistem inferensi fuzzy yang diimplementasikan dalam kerangka jaringan adaptif.. Sistem inferensi fuzzy yang digunakan adalah model fuzzy Tagaki-Sugeno-Kang (TSK) untuk kemudahan komputasi. Dalam pengendalian suhu dan level air pada tanaman hidroponik ini, akan dibuat menggunakan sistem fuzzy logic menggunakan metode Mamdani dan selanjutnya data yang diperoleh akan diolah kembali menggunakan sistem ANFIS.

\section{METODE PENELITIAN}

\subsection{Kendali Logika Fuzzy}

Kendali Logika Fuzzy adalah metodologi kontrol yang digunakan oleh manusia untuk mendeskripsikan sistem fisik dan mendefinisikan strategi kontrol yang dipakai didalamnya. Logika Fuzzy merupakan salah satu komponen pembentuk soft computing. Logika fuzzy pertama kalidiperkenalkan oleh Prof.Lotfi A. Zadeh pada tahun 1965.Dasar logika fuzzy adalah teori himpunan fuzzy. Nilaikeanggotaan atau derajat keanggotaan merupakan ciri utamadari penalaran logika fuzzy [3].

Sistem fuzzy terdiri dari beberapa tahap, yaitu :

a. Fuzzifikasi

Digunakan untuk memetakan dan mengubah atau mengkonversi masukan yang bersifat crips menjadi suatu bilangan fuzzy. Bagian pada fuzzifikasi yang digunakan untuk memetakan adalah fungsi keanggotaan(membership function). Fungsi keanggotaan merupakan suatu range nilai yang dapat mempresentasikan bentuk masukan atau keluaran sistem. Fungsi keanggotaan fuzzy ini digunakan untuk memetakan masukan ke derajat keanggotaan fuzzy.

b. Rule base

Digunakan sebagai aturan dasar pada proses kendali yang mendefinisikan himpinan fuzzy atas daerah-daerah masukan dan keluaran yang telah ditentukan, rule-base ini menggunakan logika if-then.

c. Fuzzy Inference System

Digunakan untuk mengolah masukan yang telah difuzzifikasikan, dan menyimpulkan masukan tersebut berdasarkan rule base menjadi output. Inferenceengine menggunakan metode Sugeno.

d. Defuzzifikasi

\subsection{Metode Mamdani}

Metode Mamdani merupakan metode yang paling sering digunakan dalam aplikasi-aplikasi karena strukturnya yang sederhana, yaitu menggunakan operasi MIN-MAX atau MAXPRODUCT. Dalam mendapatkan outputnya diperlukan 4 tahapan berikut : [4]

a. Fuzzifikasi

b. Pembentukan basis pengetahuan Fuzzy (rule dalam bentuk IF...THEN)

c. Aplikasi fungsi implikas menggunakan fungsi MIN dan komposisi antar-rule menggunakan fungsi MAX

d. Defuzzifikasi menggunakan metode Centroid

\subsection{Adaptive Neuro-Fuzzy Inference System (ANFIS)}

ANFIS mengandaikan bahwa input dan output dari suatu black box system (sistem kotak hitam) telah tersedia, dan ingin menebak model apa yang cocok atau yang sebenarnya ada dalam kotak hitam tersebut. Dalam menebak, tidak diisyaratkan tersedianya struktur model tertentu berdasar pada karakteristik variabel-variabel sistem. 


\section{Keterbatasan ANFIS}

Dengan kemampuannya untuk belajar menirukan kelakuak suatu sistem yang hanya berdasar pada data input dan output, anfis sebenarnya jauh lebih kompleks daripada FIS. Secara khusus anfis hanya bekerja dengan sistem-sistem Sugeno yang memiliki ciri-ciri sebagai berikut :

1. Sistem order 0 atau 1.

2. Mempunyai output tunggal yang diperoleh dari wighted average defuzzification.

3. Semua fungsi keanggotaan output harus bertipe sama, dalam bentuk konstanta atau persamaan linier.

4. Tiap Rule harus mempunyai fungsi keanggotaan keluaran yang berbeda dengan semua rule laiinya. Dengan kata lain, jumlah fungsi keanggotaan keluaran harus sama dengan jumlah rule.

5. Bobot tiap rule adalah 1. [5]

\subsection{Arsitektur ANFIS}

Misalkan terdapat 2 input $\mathrm{x}$ dan $\mathrm{y}$ dengan masing-masing input memiliki 2 buah fungsi keanggotaan. Output jaringan yang dihasilkan yaitu f dengan 2 buah fungsi keanggotaan. Jika dalam suatu sistem hanya membutuhkan 2 buah aturan sebagai berikut :

If $\mathrm{x}$ is $\mathrm{A} 1$ and $\mathrm{y}$ is $\mathrm{B} 1$ then $\mathrm{f} 1=\mathrm{p}_{11} \mathrm{x}_{1}+\mathrm{q}_{12} \mathrm{X}_{2}+\mathrm{r}_{10}$

If $\mathrm{x}$ is $\mathrm{A} 2$ and $\mathrm{y}$ is $\mathrm{B} 2$ then $\mathrm{f} 2=\mathrm{p}_{21} \mathrm{x} 1+\mathrm{q}_{22} \mathrm{x} 2+\mathrm{r}_{20}$

maka dapat dihitung nilai rata-rata terbobot sebagai keluaran jaringan (f ) dengan nilai firing strength untuk kedua aturan adalah $\mathrm{w}_{1}$ dan $\mathrm{w}_{2}$ :

$f=\frac{w_{1} f_{1}+w_{1} f_{2}}{w_{1} w_{2}}=\bar{w}_{1} f_{1}+\bar{w}_{2} f_{2}$

ANFIS dibentuk dengan arsitektur jaringan seperti neural network yang memiliki beberapa lapisan terdiri dari lapisan input, lapisan tersembunyi, serta lapisan output. Pada setiap lapisan terdapat proses perhitungan yang pada akhirnya akan menghasilkan output jaringan ANFIS. Arsitektur jaringan ANFIS dengan 5 lapisan ditampilkan pada gambar 1.

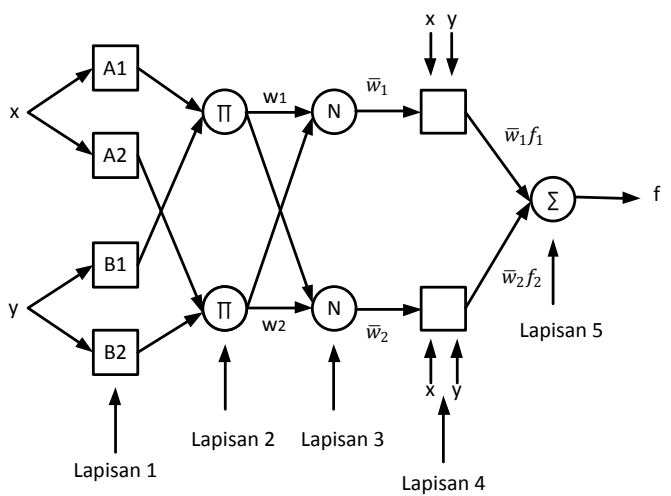

Gambar 1. Struktur ANFIS

Jaringan ANFIS, terdiri dari lapisan-lapisan berikut :

- Lapisan 1

Tiap neuron pada lapisan pertama adaptif terhadap parameter suatu fungsi aktivasi. Output dari tiap neuron merupakan derajat keanggotaan input, yaitu $\mu_{\mathrm{A} 1}(\mathrm{x}), \mu_{\mathrm{B} 1}(\mathrm{y}), \mu_{\mathrm{A} 2}(\mathrm{x}), \mu_{\mathrm{B} 2}(\mathrm{y})$. Fungsi simpul pada lapisan ini adalah :

$\mathrm{O}_{1, \mathrm{i}}=\mu_{\mathrm{Ai}}(\mathrm{x})$ untuk $\mathrm{i}=1,2$ 
$\mathrm{O}_{1, \mathrm{i}}=\mu_{\mathrm{Bi}}(\mathrm{y})$ untuk $\mathrm{i}=1,2$

$(\mathrm{a}, \mathrm{b})$ adalah parameter-parameter. Parameter-parameter lapisan ini dikenal dengan nama premise parameters.

- Lapisan 2

Pada lapisan ini berlaku operasi perkalian AND antara nilai fuzifikasi dari titik yang ada sebelumnya sebagai proses implikasi fuzzy.. Persamaan keluaran pada simpul ini adalah :

$\mathrm{O}_{2, \mathrm{i}}=\mathrm{w}_{\mathrm{i}}=\mu_{\mathrm{Ai}}(\mathrm{x}) \cdot \mu_{\mathrm{Bi}}(\mathrm{y})$ untuk $\mathrm{i}=1,2$

- Lapisan 3

Masing-masing neuron di lapiasan ini merupakan simpul tetap yang diperoleh dari hasil perhitungan rasio antara aturan derajat keanggotaan ke-I dengan jumlah seluruh aturan derajat keanggotaan, yang dapat dirumuskan sebagai berikut :

$\mathrm{O}_{3, \mathrm{i}}=\bar{w}_{i}=\frac{w_{i}}{w_{1}+w_{2}}, i=1,2$

Hasil ini dikenal dengan normalizes firing stregth.

- Lapisan 4

Setiap neuron pada lapisan ini merupakan simpul adaptif terhadap suatu output:

$\mathrm{O}_{4, \mathrm{I}}=\bar{w}_{i} f_{i}=\bar{w}_{l}\left(p_{i} x_{1}+q_{i} x_{2}+r_{i}\right)$

Dengan $\bar{w}_{l}$ adalah normalizzed firing strength pada lapisan ke-3 dan $\left(\mathrm{p}_{\mathrm{i}}, \mathrm{q}_{\mathrm{i}}, \mathrm{r}_{\mathrm{i}}\right)$ adalah parameter-parameter pada neuron tersebut. Lapisan ini disebut consequet paramaters.

- Lapisan 5

Output Layer. Setiap neuron pada lapisan ini merpakan simpul tunggal tetap yang menghitung keluaran dengan cara menjumlahkan semua masukan. [6-7]

$\mathrm{O}_{5, \mathrm{i}}=\sum \bar{w}_{i} f_{i}=\frac{\sum_{i} w_{i} f_{i}}{\sum_{i} f_{i}}$

\subsection{Pembentukan Himpunan Fuzzy}

Langkah pertama dalam membuat kontrol suhu dan tinggi air pada sistem hidroponik ini adalah dengan membentuk himpunan fuzzy terlebih dahulu. Himpunan Fuzzy yang akan dibentuk menggunakan metode Sugeno dengan dua input dan dua output.

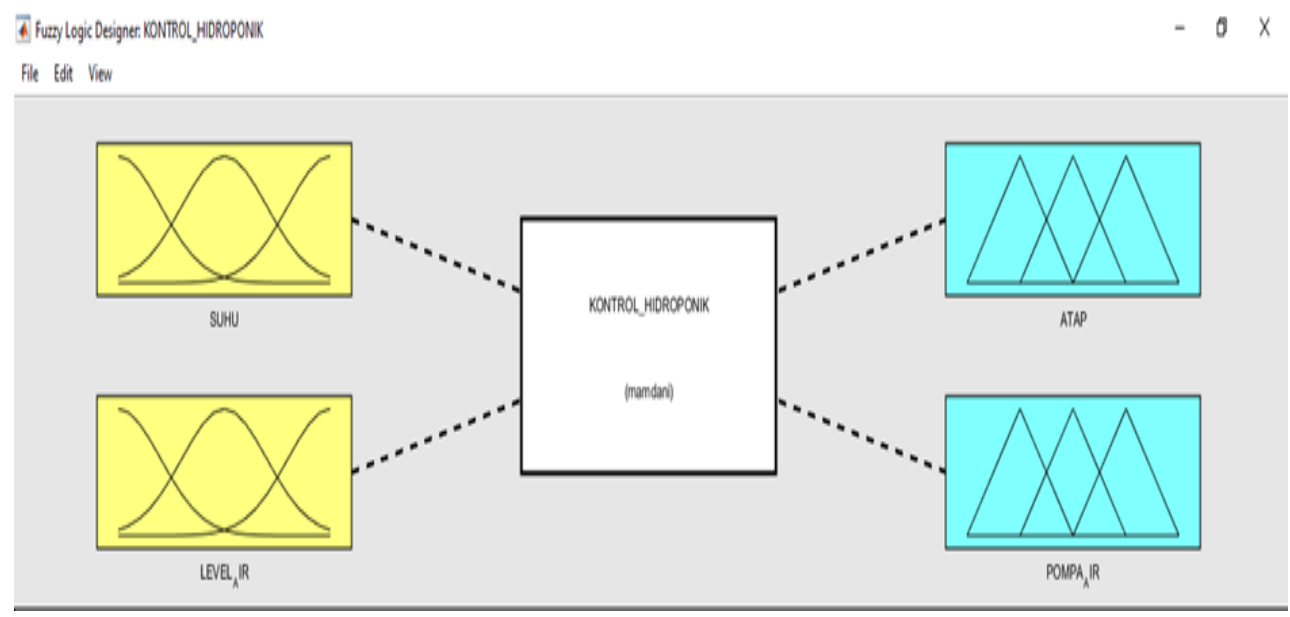

Gambar 2. Fuzzifikasi Input dan Output

\subsection{Menentukan Variabel Input}

Ada dua variabel input yang ditentukan, yaitu variabel suhu dan variabel level air. Parameter nilai suhu yang akan dipakai adalah dalam derajat celsius. Fungsi keanggotaan suhu dibagi menjadi lima himpunan fuzzy yaitu $\{\mathrm{D}, \mathrm{AD}, \mathrm{N}, \mathrm{AP}, \mathrm{P}\}$. Diagram fungsi keanggotaan dari variabel dapat 
dilihat pada gambar 3(a). Parameter nilai level keanggotaan level air yang dipakai pada alat ini adalah $\mathrm{cm}$, yaitu jarak ketinggian air dari dasar bak penampungan utama. Fungsi keanggotaan air juga dibagi menjadi lima himpunan fuzzy yaitu $\{\mathrm{R}, \mathrm{AR}, \mathrm{N}, \mathrm{AT}, \mathrm{T}\}$. Diagram fungsi keanggotaan dari variabel air dapat dilihat pada gambar 3(b).

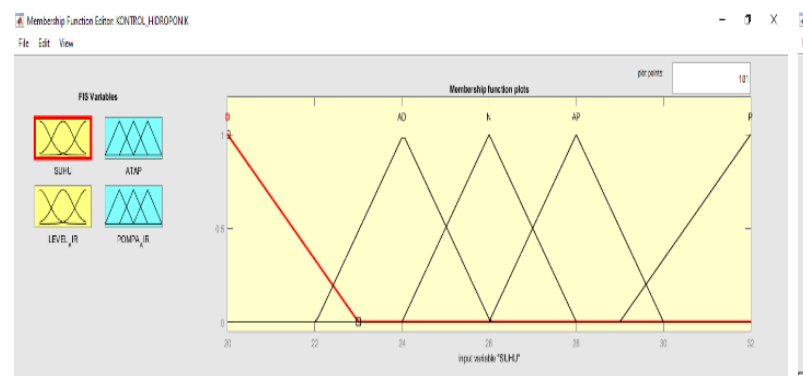

(a)

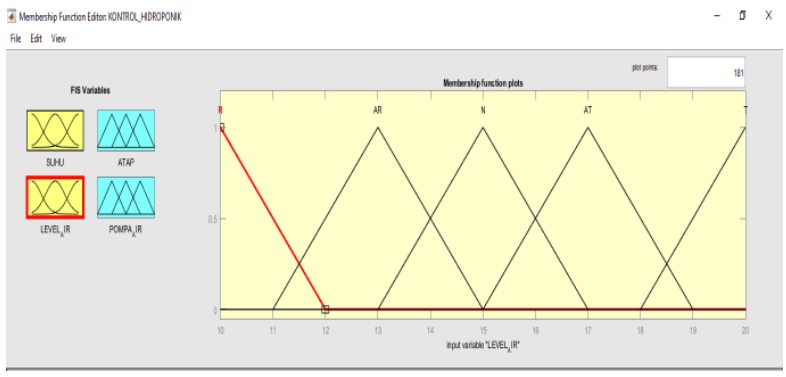

(b)

Gambar 3. (a) Variabel Suhu, (b) Variabel Level Air

\subsection{Menentukan Variabel Output}

Ada dua variabel output yang ditentukan, yaitu output atap dan pompa. Variabel membuka dan menutup atap dibagi menjadi lima himpunan yaitu $\{$ FT,SM,STM,TPM,FM $\}$. Diagram fungsi keanggotaan dari variabel atap dapat dilihat pada gambar 4(a) .Variabel pompa air juga dibagi menjadi lima himpunan yaitu $\{\mathrm{S}, \mathrm{AS}, \mathrm{N}, \mathrm{AT}, \mathrm{T}\}$. Diagram fungsi keanggotaan dari variabel on dan off nya pompa air dapat dilihat pada gambar $4(\mathrm{~b})$.

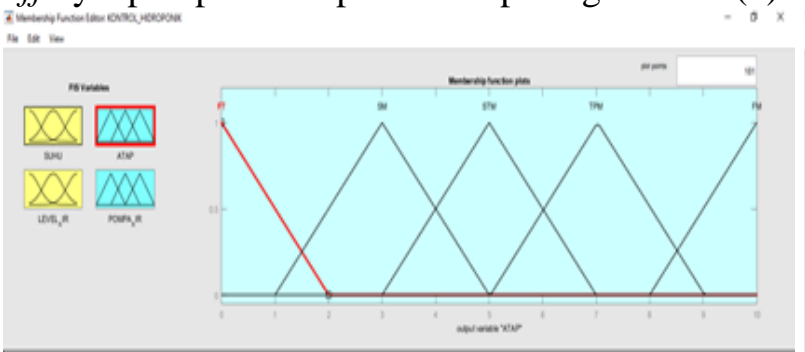

(a)

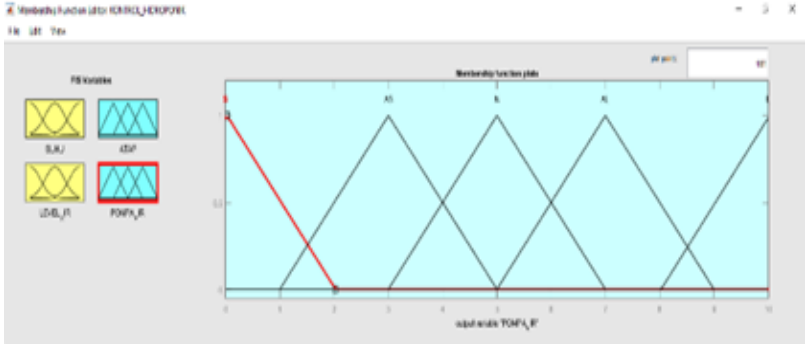

(b)

Gambar 4. (a) Variabel Atap, (b) Variabel Pompa Air

\subsection{Menentukan Rules Fuzzy}

Setelah menentukan variabel input dan output, langkah selanjutnya adalah menentukan rules fuzzy. Adapun rules fuzzy yang dibuat adalah seperti pada tabel.1 dibawah ini

Tabel 1. Deskripsi Aturan Fuzzy Mamdani

\begin{tabular}{cl}
\hline No & Deskripsi Aturan Fuzzy \\
\hline 1 & If (suhu is D) and (level air is R) then (atap is FM)(Pompa air is L) \\
2 & If (suhu is D) and (level air is AR) then (atap is FM)(Pompa air is AL) \\
3 & If (suhu is D) and (level air is N) then (atap is FM)(Pompa air is N) \\
4 & If (suhu is D) and (level air is AT) then (atap is FM)(Pompa air is AS) \\
5 & If (suhu is D) and (level air is T) then (atap is FM)(Pompa air is L) \\
6 & If (suhu is AD) and (level air is R) then (atap is TPM)(Pompa air is L) \\
7 & If (suhu is AD) and (level air is AR) then (atap is TPM)(Pompa air is AL) \\
8 & If (suhu is AD) and (level air is N) then (atap is TPM)(Pompa air is N) \\
9 & If (suhu is AD) and (level air is AT) then (atap is TPM)(Pompa air is AS) \\
10 & If (suhu is AD) and (level air is T) then (atap is TPM)(Pompa air is S) \\
11 & If (suhu is P) and (level air is R) then (atap is FT)(Pompa air is L)
\end{tabular}


12 If (suhu is P) and (level air is AR) then (atap is FT)(Pompa air is AL)

13 If (suhu is P) and (level air is N) then (atap is FT)(Pompa air is N)

14 If (suhu is P) and (level air is AT) then (atap is FT)(Pompa air is AS)

15 If (suhu is P) and (level air is T) then (atap is FT)(Pompa air is S)

16 If (suhu is AP) and (level air is R) then (atap is SM)(Pompa air is L)

17 If (suhu is AP) and (level air isAR) then (atap is SM)(Pompa air is AL)

18 If (suhu is AP) and (level air is N) then (atap is SM)(Pompa air is N)

19 If (suhu is AP) and (level air is AT) then (atap is SM)(Pompa air is AS)

20 If (suhu is AP) and (level air is T) then (atap is SM)(Pompa air is S)

21 If (suhu is N) and (level air is R) then (atap is STM)(Pompa air is L)

22 If (suhu is N) and (level air isAR) then (atap is STM)(Pompa air is AL)

23 If (suhu is N) and (level air is N) then (atap is STM)(Pompa air is N)

24 If (suhu is N) and (level air is AT) then (atap is STM)(Pompa air is AS)

25 If (suhu is N) and (level air is T) then (atap is STM)(Pompa air is S)

\subsection{Membuat Sistem Kontrol Suhu dan Level Air Menggunakan Simulink}

Dengan menggunakan simulink, kita dapat membuat simulasi fuzzy logic dari asistem pengaturan suhu dan level air seperti pada gambar 5.

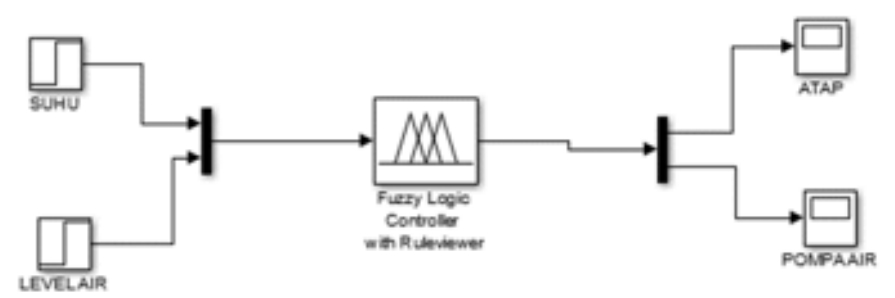

Gambar 5. Simulasi Fuzzy Menggunakan Simulink

\section{HASIL DAN PEMBAHASAN( TIMES NEW ROMAN 11PT CAPITAL BOLD)}

Dengan menggunakan aplikasi dari matlab, kita dapat melihat hasil rule viewer dari masingmasing setpoint yang kita tentukan. Hal ini dapat dilihat pada gambar 6. 


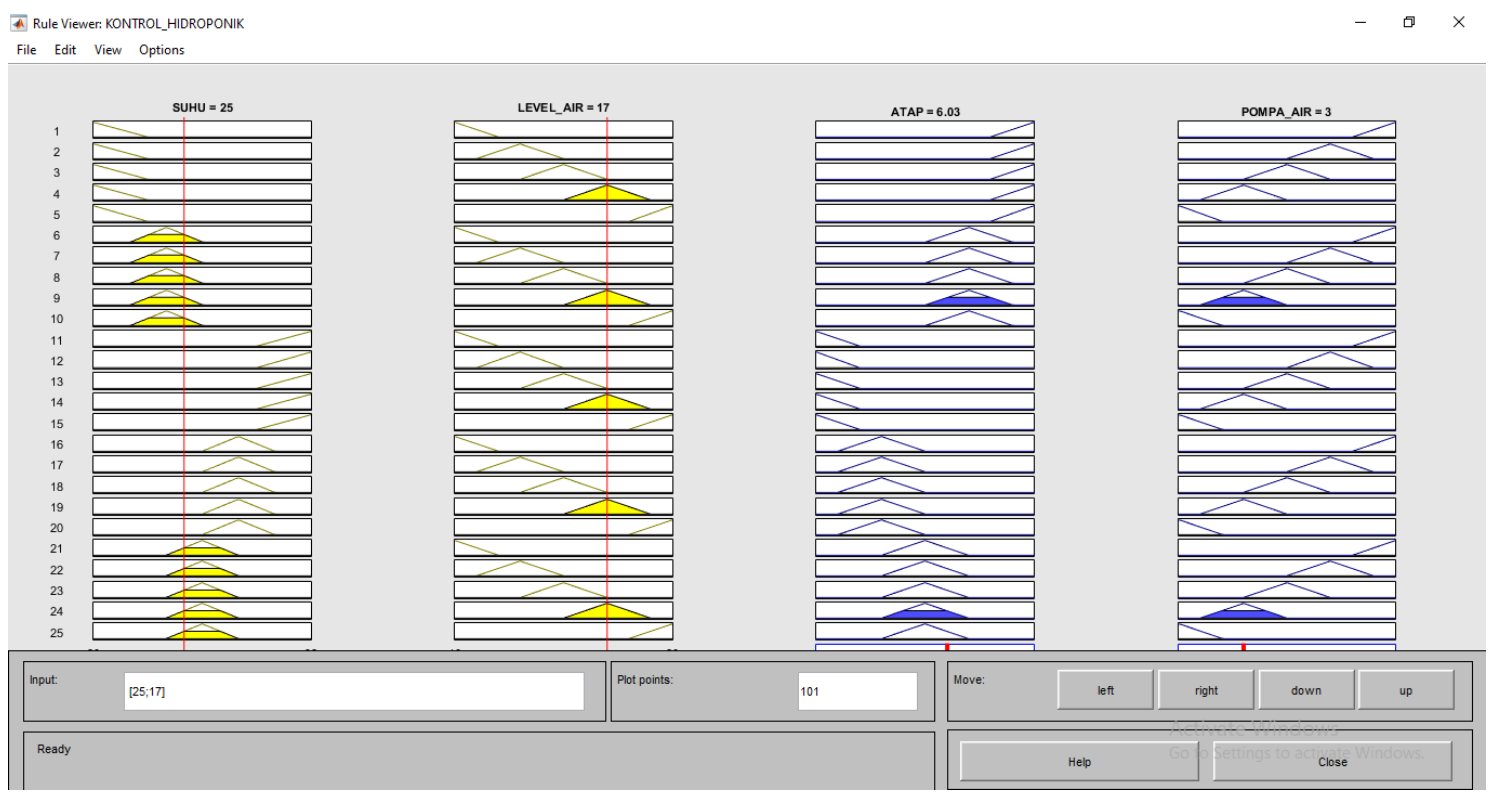

Gambar 6. Hasil Rule Viewer

Kita juga dapat melihat hasil simulasi melalui simulink dengan memasukkan beberapa nilai setpoint, seperti pada gambar 7. Untuk gambar 7(a) diberikan setpoint suhu $=20$ dan level air $=10$, gambar 7(b) diberikan setpoint suhu= 20 dan level air $=12$, gambar 7(c) diberikan setpoint suhu $=23$ dan level air= 19, sedangkan gambar 7(d) diberikan setpoint suhu $=25$ dan level air $=15$

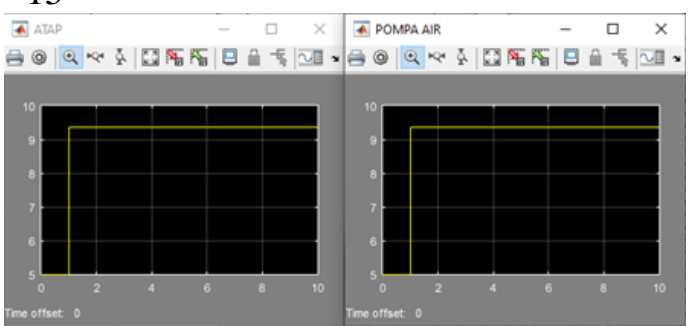

(a)

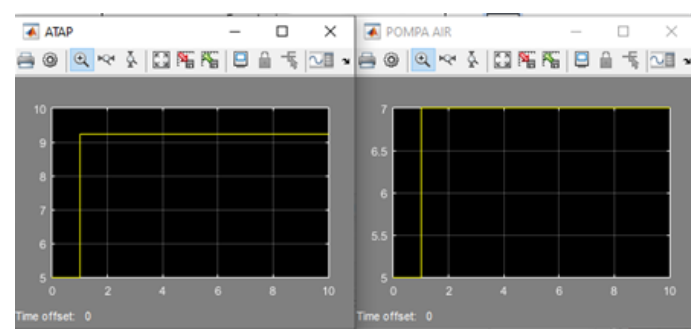

(b)

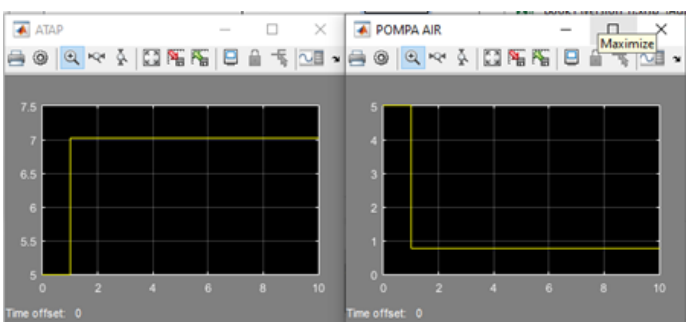

(c)

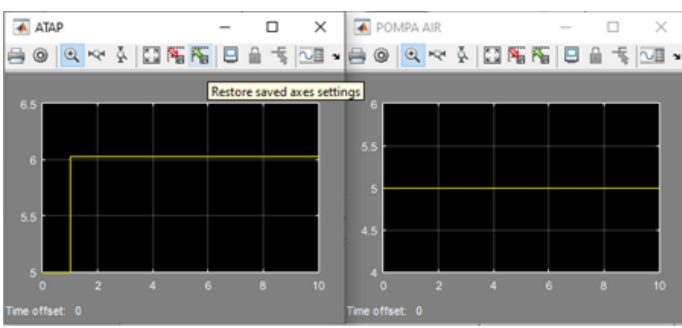

(d)

Gambar 7. Tampilan Hasil Simulasi Menggunakan Simulink

Tabel 2 merangkum hasil output menggunakan metode Mamdani dengan memasukkan beberapa setpoint nilai input suhu dan level air.

Tabel 2. Hasil Fuzzifikasi Output Metode Mamdani

\begin{tabular}{ccccc}
\hline \multirow{2}{*}{ No } & \multicolumn{2}{c}{ Input } & \multicolumn{2}{c}{ Output } \\
\cline { 2 - 4 } & Suhu & Level Air & Atap & Pompa \\
\hline
\end{tabular}




\begin{tabular}{ccccc}
\hline 1 & 20 & 10 & 9.37 & 9.37 \\
2 & 20 & 12 & 9.25 & 7 \\
3 & 20 & 15 & 9.37 & 5 \\
4 & 20 & 17 & 9.37 & 3 \\
5 & 20 & 19 & 9.25 & 0.765 \\
6 & 23 & 10 & 7.03 & 9.25 \\
7 & 23 & 12 & 7.03 & 7 \\
8 & 23 & 15 & 7.03 & 5 \\
9 & 23 & 17 & 7.03 & 3 \\
10 & 23 & 19 & 7.03 & 0.771 \\
11 & 25 & 10 & 6.03 & 9.27 \\
12 & 25 & 12 & 6.03 & 7 \\
13 & 25 & 15 & 6.03 & 5 \\
14 & 25 & 17 & 6.03 & 3 \\
15 & 25 & 19 & 6.01 & 0.765 \\
16 & 28 & 10 & 3 & 9.37 \\
17 & 28 & 12 & 3 & 7 \\
18 & 28 & 15 & 3 & 5 \\
19 & 28 & 17 & 3 & 3 \\
20 & 28 & 19 & 3 & 0.765 \\
21 & 30 & 10 & 0.818 & 9.19 \\
22 & 30 & 12 & 0.818 & 7 \\
23 & 30 & 15 & 0.818 & 5 \\
24 & 30 & 17 & 0.818 & 3 \\
25 & 30 & 19 & 0.818 & 0.832 \\
\hline & & & &
\end{tabular}

Setelah di uji coba menggunakan simulasi fuzzy dengan menggunakan metode Mamdani, kemudian data diolah kembali menggunakan sistem Adaptivel Neuro Fuzzy Inference System (ANFIS). Dengan hasil strukturnya nya seperti pada gambar 8

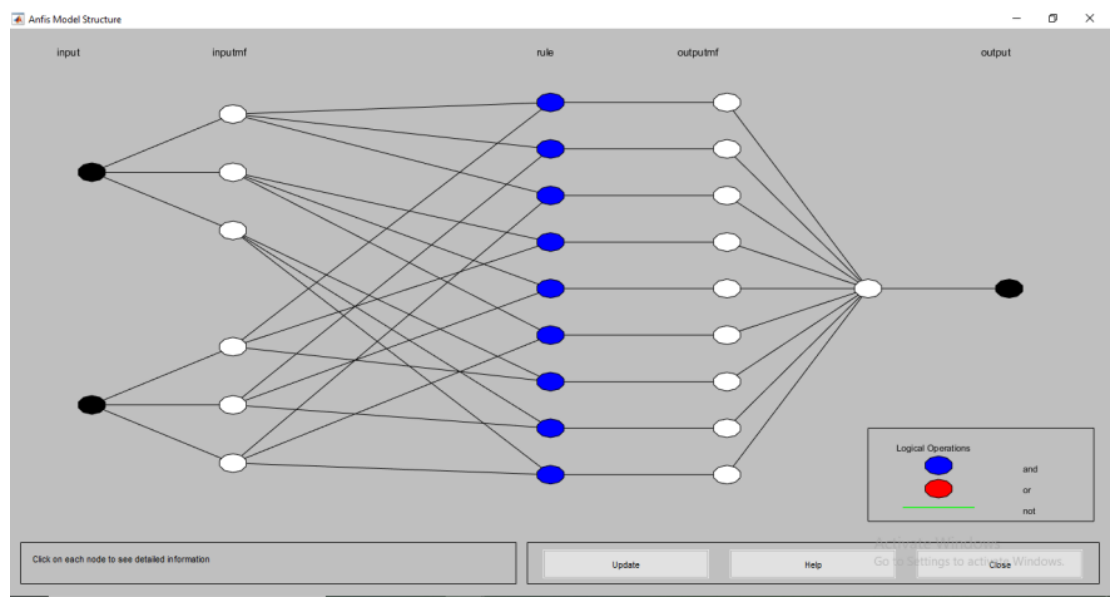

\section{Gambar 8. Struktur ANFIS kontrol hidroponik}

Berdasarkan data pada tabel. 2 didapatkan hasil untuk training data output atap seperti gambar 9 . Dari hasil training dengan nilai epochs 30 rata-rata error yang didapat adalah 0,0079496. 


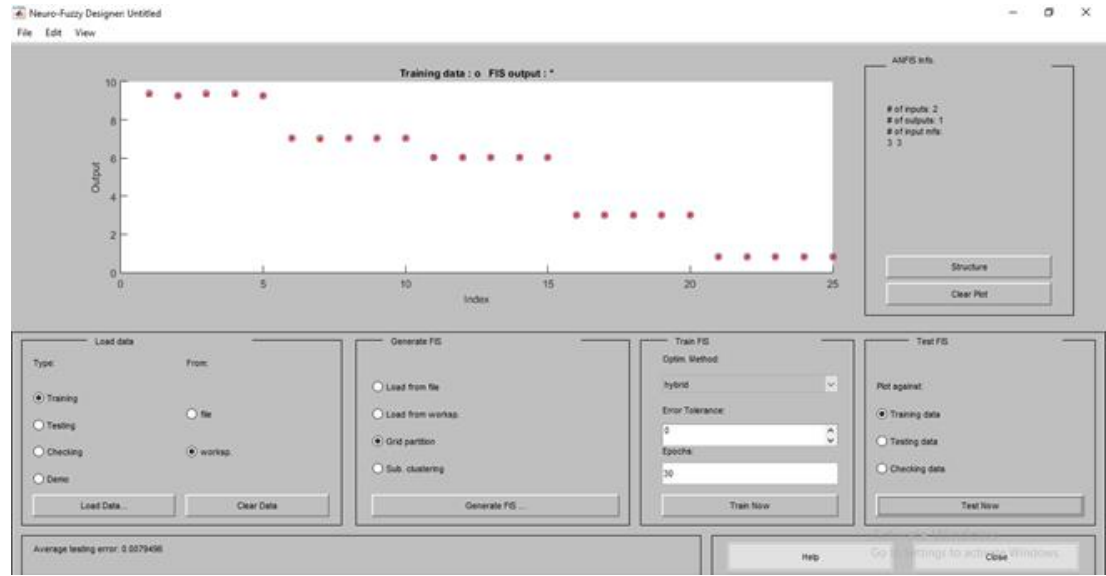

Gambar 9. Hasil Training Output Atap

Sedangkan untuk taining data output pompa air ditampilkan pada gambar 10. Dari hasil training dengan nilai epochs 30 rata-rata eror yang didapat adalah 0,01296

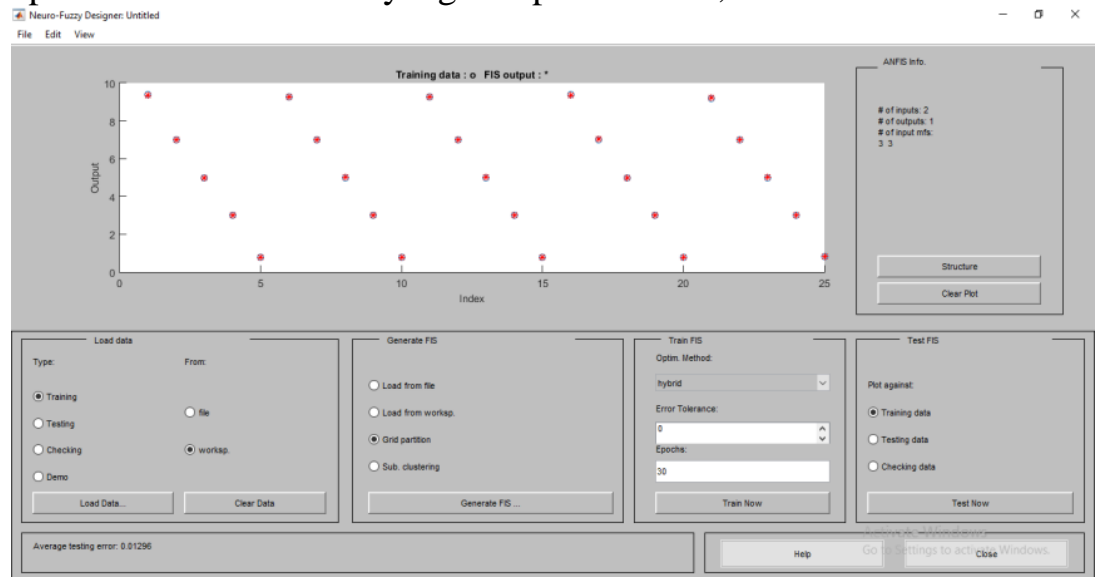

Gambar 10. Hasil Training Output Pompa Air

Hasil fuzzifikasi menggunakan ANFIS dapat dilihat pada tabel 3.

Tabel 3. Hasil fuzzifikasi menggunakan metode ANFIS

\begin{tabular}{ccccccc}
\hline \multirow{2}{*}{ No } & \multicolumn{2}{c}{ Input } & \multicolumn{2}{c}{ Output } & \multicolumn{2}{c}{ Selisih dengan Mamdani } \\
\cline { 2 - 7 } & Suhu & Level Air & Atap & Pompa & Atap & Pompa \\
\hline 1 & 20 & 10 & 9.37 & 9.37 & 0 & 0 \\
2 & 20 & 12 & 9.26 & 7.01 & 0.01 & 0.01 \\
3 & 20 & 15 & 9.37 & 5 & 0 & 0 \\
4 & 20 & 17 & 9.36 & 3 & 0.01 & 0 \\
5 & 20 & 19 & 9.25 & 0.767 & 0 & 0.002 \\
6 & 23 & 10 & 7.04 & 9.26 & 0.01 & 0.01 \\
7 & 23 & 12 & 7.01 & 6.98 & 0.02 & 0.02 \\
8 & 23 & 15 & 7.03 & 5.01 & 0 & 0.01 \\
9 & 23 & 17 & 7.05 & 3.01 & 0.02 & 0.01 \\
10 & 23 & 19 & 7.02 & 0.767 & 0.01 & 0.004 \\
11 & 25 & 10 & 6.02 & 9.27 & 0.01 & 0 \\
12 & 25 & 12 & 6.04 & 7 & 0.01 & 0 \\
13 & 25 & 15 & 6.03 & 5 & 0 & 0
\end{tabular}




\begin{tabular}{ccccccc}
14 & 25 & 17 & 6.02 & 3 & 0.01 & 0 \\
15 & 25 & 19 & 6.02 & 0.763 & 0.01 & 0.002 \\
16 & 28 & 10 & 3 & 9.35 & 0 & 0.02 \\
17 & 28 & 12 & 3 & 7.04 & 0 & 0.04 \\
18 & 28 & 15 & 3 & 4.99 & 0 & 0.01 \\
19 & 28 & 17 & 3 & 2.98 & 0 & 0.02 \\
20 & 28 & 19 & 3 & 0.775 & 0 & 0.01 \\
21 & 30 & 10 & 0.819 & 9.2 & 0.001 & 0.01 \\
22 & 30 & 12 & 0.816 & 6.98 & 0.002 & 0.02 \\
23 & 30 & 15 & 0.819 & 5.01 & 0.001 & 0.01 \\
24 & 30 & 17 & 0.819 & 3.01 & 0.001 & 0.01 \\
25 & 30 & 19 & 0.818 & 0.826 & 0 & 0.006 \\
\hline
\end{tabular}

Berdasarkan hasil yang diperoleh antara fuzzifikasi dengan metode Mamdani dan metode ANFIS, untuk atap terdapat selisih antara 0.001 sampai 0.02 , sedangkan untuk pompa air terdapat selisih antara 0.006 sampai dengan 0.01 .

\section{KESIMPULAN}

Dari hasil simulasi yang telah dilakukan, antara sistem fuzzy menggunakan metode Mamdani dan sistem yang menggunakan ANFIS terdapat selisih antara 0.006 hingga 0.01. Sehingga untuk pengontrolan suhu dan level air pada sistem hidroponik, ANFIS dapat memberikan hasil yang lebih akurat, walaupun nilai selisih yang diperoleh tidaklah terlalu signifikan.

\section{DAFTAR PUSTAKA}

[1] Wang, J.S., Lee, C.S.G.,2002 "Self-Adaptive Neuro-Fuzzy Inference Systems forClassification Applications", IEEE Trans. on Fuzzy Systems, 10, 6, Dec.

[2] Syahputra, R., Robandi, I., and Ashari, M., 2014a, "Optimization of DistributionNetwork Configuration with Integration of Distributed Energy Resources Using Extended Fuzzy Multi-objective Method", International Review of Electrical Engineering (IREE), vol.9, no.3, pp. 629-639.

[3] Kusumadewi,Sri,dkk.2010. "Buku Aplikasi Logika Fuzzy untuk Pendukung Keputusan". Edisi 2. Graha Ilmu. Yogyakarta (2-47)

[4] T.Sutojo dkk, 2010. "Kecerdasan Buatan" , Penerbit Andi Offset . Yogyakarta (235)

[5] Agus Naba, 2009 ,"Belajar Cepat Fuzzy Logic Menggunakan MATLAB,"Penerbit Andi Offset . Yogyakarta (118-120).

[6] Jang, J-S, dkk.,Neuro-Fuzzy and Soft Computing, Prentice-Hall International, Inc., 1997.

[7] Kusumadewi, Sri dan Sri Hartati, 2010, "Neuro-Fuzzy Integrasi Sistem Fuzzy \& Jaringan Syaraf" Edisi2, Penerbit Graha Ilmu, Yogyakarta 